\title{
O DILEMA JURÍDICO DA PROPRIEDADE INTELECTUAL NA INTELIGÊNCIA ARTIFICIAL: A MÁQUINA PODERÁ SER TITULAR DE DIREITO AUTORAL?
}

\author{
Jaqueline Silva Paulichi ${ }^{1}$ \\ Matheus Ribeiro de Oliveira Wolowski ${ }^{2}$
}

Resumo: $O$ artigo tem como objetivo analisar o contexto da inteligência artificial na sociedade e suscitar um problema que o Direito precisa resolver: O direito autoral de um algoritmo que desenvolve uma marca ou patente. Para isso, utiliza-se do método teórico abordando aspectos panorâmicos sobre a inteligência artificial e o que o ordenamento jurídico vigente regula sobre a propriedade intelectual. Como nem o desenvolvedor e nem o comprador conseguirão prever o que um software autônomo poderá produzir, conclui-se que é imprescindível uma regulamentação dessa questão a fim de se evitar litígios e assegurar a proteção aos direitos autorais.

Palavras-chaves: Inteligência Artificial. Propriedade Intelectual. Direitos da personalidade. Aprendizado Máquina. Direitos Autorais.

\section{THE LEGAL DILEMMA OF INTELLECTUAL PROPERTY IN ARTIFICIAL INTELLIGENCE: CAN THE MACHINE BE A COPYRIGHT HOLDER?}

\begin{abstract}
The article aims to analyze the context of intelligence in artificial society and raise a problem that the Law needs to solve: The copyright of an algorithm that adapts a trademark or patent. For this, the theoretical method is used, approaching panoramic aspects about artificial intelligence and what the current legal system regulates about intellectual property. As neither the developer nor the purchaser will be able to predict what a standalone software can produce, it follows that a need for this issue is essential in order to avoid litigation and ensure copyright protection.
\end{abstract}

Keywords: Artificial intelligence. Intellectual property. Personality rights. machine learning. Copyright.

\section{INTRODUÇÃO}

Serão apresentados neste trabalho os conceitos relativos à inteligência artificial e seus impactos na criação de softwares que possam criar novas obras intelectuais. Questiona-se

\footnotetext{
${ }^{1}$ Doutoranda em Ciências Jurídicas pena Unicesumar- Bolsista Prosup. Mestre no Programa de Mestrado em Direitos da Personalidade do Centro Universitário Cesumar (UNICESUMAR); Especialista em Direito Aplicado pela Escola da Magistratura do Paraná (EMAP); Advogada em Maringá-PR. Especialista em Direito Civil e Processo Civil. Especialista em Direito Público. Professora de Direito Civil, Advogada. E-mail j.paulichi@hotmail.com.

${ }_{2}$ Doutorando em Direito pela Unicesumar - Bolsista PROSUP/CAPES; Mestre em Ciências Jurídicas Pela Unicesumar; Graduado em Direito e teologia pela Unicesumar; Professor da Universidade Estadual de MaringáPR e advogado; E-mail: matheuswolowski@hotmail.com
} 
acerca do direito autoral decorrente do uso das novas tecnologias que possam criar através de inteligência artificial e base de dados novas obras de arte, vídeos e sons.

A lei 9.610 de 1998 trata do direito do autor e não menciona acerca das novas tecnologias, abrangendo a proteção ao software, mas não às criações decorrentes do uso deste. A lei 9.609 de 1998 trata dos softwares especificamente, mas não trata das obras decorrentes desses programas.

Procura-se demonstrar quais são as indagações a respeito da ausência de legislação específica acerca do tema, bem como a desproteção existente com autores que possuem suas obras em bases de dados para a confecção de novas obras. Enquanto não houver legislação sobre o tema, casos que tratam do uso imoderado das novas tecnologias serão analisados no poder judiciário, gerando insegurança jurídica para aqueles que trabalham com isso.

$\mathrm{O}$ texto inicia apresentando os conceitos relativos à inteligência artificial e sua relevância para a sociedade moderna, bem como os conceitos de machine learning e deep learning, para após apontar os pontos mais pertinentes da lei de direitos autorais neste trabalho. Logo após será analisado o contexto da proteção ao autor no caso de obras criadas através de novas tecnologias, para ao fim apontar as indagações a respeito do tema.

\section{APONTAMENTOS DA INTELIGÊNCIA ARTIFICIAL NA CONTEMPORANEIDADE}

Tal qual ocorreu na revolução industrial, com o advento das máquinas de produção, a Inteligência Artificial tem evoluído constantemente na sociedade contemporânea e, de forma gradativa, vem sendo inserida em diversos setores da sociedade, como ferramenta de auxílio para análises preditivas de mercado, intervenções cirúrgicas, transportes autônomos, bens de consumo e análises jurídicas, dentre outros.

Alan Turing é considerado um dos principais precursores da Inteligência Artificial. O matemático desenvolveu uma linguagem artificial que serviu de base para o desenvolvimento da inteligência artificial:

Suas propostas podem ser resumidas nos resultados de dois artigos inovadores: no primeiro, Turing [8] introduziu máquinas $\alpha$-abstratas, enquanto o segundo [9] lançou as bases para o programa de pesquisa de Inteligência Artificial clássico, que durou pelo menos entre os 1950 e 1990 . O modelo abstrato de computação, logo conhecido como Universal Turing Machine (UTM), tornou-se a base teórica para as primeiras máquinas de computação modernas construídas por John von Neumann nos Estados Unidos e por Max Newman no Reino Unido no final dos anos 1940, e tornou-se a 
arquitetura básica dos computadores. Mas o ponto crucial é sua demonstração de que existem tarefas matemáticas que não podem ser realizadas por meio de um método eficaz. Onde o método eficaz é um método que pode ser calculado mecanicamente por algum UTM. (GELICIC, 2018, p. 18-19)

Essa questão é fruto do que se denomina como indústria 4.0, uma vez que há o rompimento das balizas até então existentes com o advento da tecnologia inteligente. Esse movimento denominado de indústria 4.0 foi protagonizado originariamente em 1956.

\begin{abstract}
A 4a Revolução Industrial (indústria 4.0) caracteriza-se pela eliminação de todas as fronteiras físicas, biológicas e digitais, se diferenciando das demais em razão da sua velocidade, profundidade e impacto sistêmico que a conduz. Um dos pilares da indústria 4.0 é a inteligência artificial (IA) que tem origem em 1956 quando John McCarthy utilizou o termo numa conferência de especialistas celebrada em Darmouth Colege. (DAMILANO, 2019, p.19986)
\end{abstract}

Atualmente, tem-se como definição do termo Inteligência Artificial - IA ou AI (Artificial Intelligence) - a capacidade de desenvolvimento de inteligência nos robôs, a qual alguns denominam racionalidade (RUSSELL; NORVIG, 2009, p.1152).

Pode-se ainda, compreender tal conceito como um esforço em tornar computadores em máquinas com mentes, no sentido pleno e literal (HAUGELAND, 1985, p.287); ou —a automação de atividades associadas ao pensamento humano, como a tomada de decisões e resolução de problemas\| (BELLMAN, 1978, p.146); conceitua-se também a IA como: a arte de criar máquinas que executam funções que exigem inteligência quando realizada por pessoas. (KURZWEIL, 1990, p.580).

Por fim, a Comissão Europeia de Inteligência Artificial assevera que a Inteligência Artificial se refere a sistemas que demonstram um comportamento inteligente: A análise de seu entorno os permitem realizar diversas tarefas com certo grau de autonomia para alcançar objetivos específicos. (EUROPEAN COMISSION, 2018, p.2)

\footnotetext{
${ }^{3}$ Tradução livre - Texto original em espanhol: "Sus prepuestas se pueden resumir en los resultados de dos artículos innovadores: en el primero, Turing [8] introdujo las máquinas $\alpha$-abstractas, mientras que el segundo [9] sentó las bases del programa de investigación de la Inteligencia Artificial clásica, que perduró, por lo menos, entre las décadas de 1950 y 1990. El modelo abstracto de computación, conocido pronto como Universal Turing Machine (UTM), se convirtió en la base teórica de las primeras maquinarias informáticas modernas construidas por John von Neumann en los Estados Unidos y por Max Newman en el Reino Unido, a finales de la Década de 1940, y se convirtió en la arquitectura base de los computadores. Pero el punto crucial es su demostración de que hay tareas matemáticas que no se pueden llevar a cabo por medio de un método efectivo. Donde método efectivo es un método que puede ser calculado mecánicamente por algunas UTM." (GELICIC, 2018, p. 18-19)
} 
Bruno Felipe e Raquel Perrota, sinalizam quatro principais características dos dispositivos dotados de inteligência artificial,

Em geral, robôs autônomos, dotados de Inteligência artificial, seguem as seguintes características: (1) adquirem autonomia através de sensores e/ou através da troca de dados com o seu ambiente (interconectividade) e troca e analisa dados; (2) aprendem por si mesmos (critério opcional); (3) possuem um suporte físico; (4) adaptam o seu comportamento e as suas ações ao ambiente no qual se encontram. (FELIPE; PERROTA, 2018, p. 2)

Importante, portanto, observar que a inteligência artificial pode ser classificada como forte ou fraca. "A IA forte é definida como inteligência artificial capaz de igualar ou exceder a inteligência dos humanos. IA fraca é definida como inteligência artificial e racional que se concentra apenas em tarefas estreitas.” (GARCÍA-PEÑALVO, 2019, p. 26) ${ }^{4}$

Essa inteligência forte, se caracteriza pela semelhança da Inteligência humana, isto é, a forma de agir da máquina é aperfeiçoada de acordo com o aprendizado, a vivência, as experiências e razão e não apenas uma mera programação previamente definida. Essa evolução do Machine Learning (Aprendizado da máquina) é o que tem de mais avançado na inteligência artificial.

O aprendizado de máquina, em particular, é frequentemente descrito como o sofrimento da "maldição da dimensionalidade" (Domingos 2012). Em uma era de "big data", bilhões ou trilhões de exemplos de dados e milhares ou dezenas de milhares de propriedades dos dados (denominados "recursos" no aprendizado de máquina) podem ser analisados. A lógica de decisão interna do algoritmo é alterada à medida que 'aprende' nos dados de treinamento. - tradução nossa. (BURRELL, 2016$, p. 7$)^{5}$

Partindo dessa premissa, o Machine Learning pode ser definido como uma espécie de sistema de algoritmo, que permitem ao protótipo processar informações com forma de exemplos, sem necessidade de uma programação previamente definida, mas que se adapta com o tempo e com as experiências vivenciadas de forma interativa. Ainda sobre tal conceito, tem-se que o Machine Learning,

\footnotetext{
${ }^{4}$ Tradução Livre - Texto original em espanhol: "La IA fuerte se define como aquella inteligencia artificial capaz de igualar o exceder la inteligencia de los humanos. La IA débil se define como aquella inteligencia artificial y racional que se centra únicamente en tareas estrechas" (FELIPE; PERROTA, 2018, p. 2)

${ }^{5}$ Tradução livre - texto original em inglês: "Machine learning, in particular, is often described as suffering from the "curse of dimensionality" (Domingos 2012). In an era of "big data", billions or trillions of data examples and thousands or tens of thousands of data properties (called "features" in machine learning) can be analyzed. The algorithm's internal decision logic changes as it 'learns' from the training data." (BURREL, 2016, p.7)
} 
são habilidades da inteligência artificial que permitem a um computador ajustar operações sem programação explícita na medida em que é exposto a novas informações, já o Deep Learning é uma das várias abordagens para o machine learning, e foi inspirado na estrutura e nas funções do cérebro humano, na interligação dos neurônios. (STAATS, 2020, p.4)

Grande parte das pesquisas indicam que a relação existente entre o Direito e a Inteligência Artificial surge em meados da década de 70 com a mudança de entendimento a fim de assegurar a aceitação da interdisciplinaridade existente entre tecnologia e Direito.

\begin{abstract}
IA e Direito consistem em produto tipicamente do século XX e XXI, não simplesmente em função dos avanços tecnológicos que tornaram possível falar em IA, mas também em razão do câmbio de paradigma na forma de encarar a integração interdisciplinar das ciências como um novo modelo teórico para responder a problemas que não são mais setorizados. Ainda que tivéssemos o avanço tecnológico suficiente para realizar esta integração, ou melhor, ainda que a IA fosse uma realidade, caso não houvéssemos tido este câmbio de ordem epistemológica, não havia sido possível conectar ciências tão distintas como o Direito e a Computação (MAGALHÃES, 2005,p.361)
\end{abstract}

Nesse caminho, a expansão das tecnologias que viabilizam novos serviços de internet leva a mudanças na forma como as pessoas e as organizações interagem, gerando ambiguidades jurídicas e problemas jurídicos originais. Essas tecnologias incluem computação em nuvem, big data, Internet das coisas (IoT), inteligência artificial (AI), criptografia, sensores, robôs, algoritmos e outros sistemas relacionados à informação.

A maioria dessas tecnologias depende de infraestruturas de computação em nuvem para operar no nível superior. Um conceito específico conhecido como IoT é o principal habilitador para a conectividade de dispositivos de computação. A Internet das Coisas abraça um novo conceito pelo qual o mundo virtual da Internet converge com o mundo cotidiano das "coisas". A ideia é conectar as pessoas entre si, mas também pessoas com organizações e itens do cotidiano (SOARES; KAUFFMAN; CHAO; SAAD, 2020, p.3).

A empresa International Business Machines (IBM) definiu seis grandes categorias de possíveis aplicações da inteligência artificial ao Direito, a saber: 1) a previsão de resultados de litígios; 2) elaboração de documentos; 3) pesquisa jurídica e revisão de contratos; 4) identificação de padrões em decisões judiciais; 5) identificação de propriedade intelectual em portfólios e; 6) faturamento automático de honorários. (ROSS, 2018)

O Ross é o primeiro sistema alcunhado de "robô-advogado", que interage com o ser humano, apresentando respostas fundamentadas em frações de segundo após ser consultado. 
Sistemas similares vêm emergindo ao longo do tempo. No Brasil, tem-se o robô advogado chamado de ELI, que foi criado pela empresa Tikal tech. Esse software é capaz de realizar cálculos e petições trabalhistas, cálculos de ICMS e inúmeros contratos em poucos minutos.

Evidentemente que tais avanços apresentam pontos positivos e também negativos. Dentre os pontos positivos, verifica-se a celeridade processual, uma vez que a inteligência artificial é capaz de processar uma imensa quantidade de dados e informações em frações de segundo, que demandariam muito mais tempo se realizado por um ser humano. Todavia, desperta-se a preocupação quanto aos eventuais danos que o avanço dessa tecnologia pode acarretar, como por exemplo, julgamentos incoerentes e violação à direitos fundamentais e até mesmo impasses, envolvendo a propriedade intelectual de marcas ou patentes criadas por esses robôs.

Inúmeras são as indagações acerca dos conflitos éticos e interesses envolvendo a Inteligência Artificial e o Direito. No processo educacional, por exemplo, questiona-se o limite do uso da tecnologia no aspecto pedagógico.

Seria possível que o docente humano fosse substituído por um robô?

É evidente que os docentes humanos ainda não serão substituídos pelas máquinas, mas não se descarta essa possibilidade no futuro, visto que a tecnologia tem expandido a passos largos e paulatinamente é inserida e demandada nos processos educacionais (CARDIN; WOLOWSKI, 2021, p.191).

Tal premissa se sustenta, uma vez que os algoritmos não são capazes de ter sensibilidade humana diante de controvérsias oriundas de problemas familiares, financeiros, de saúde ou mesmo de formação básica de alguns alunos que resultam em limitações de aprendizagem para novos conteúdos. Portanto, deve-se levar em consideração a subjetividade de cada indivíduo, uma vez que nem todas as aulas possuem uma capacidade isonômica de aprender o referido conteúdo simultaneamente, no mesmo intervalo de tempo e sob a mesma língua. Contudo, é importante ressaltar que a incerteza do futuro pode perfazer com que essa sensibilidade também seja superada pela máquina.

Nesse contexto,

É importante lembrar que atualmente existe certa dependência tecnológica, que atinge toda a sociedade, desde pequenas empresas, até governos e grandes instituições. Consequentemente, as relações negociais migram para a internet, o que pode gerar riscos aos envolvidos em relação à segurança da transação que é realizada. (PAULICHI; CARDIN, 2020, p. 235) 
Portanto, considerando a impossibilidade de se conviver sem a tecnologia e a inteligência artificial na sociedade contemporânea e atual, questiona-se como seria regulado pelo Direito a propriedade intelectual desenvolvida por um sistema de IA dotado de Deep Learning, uma vez que nem o seu desenvolvedor ou adquirente consegue prever a tomada de decisão dos algoritmos. Para encontrar caminhos à essa problemática, essencial compreender como atualmente se regulamenta a propriedade intelectual desenvolvida por humanos, o que se observará no capítulo subsequente.

\section{DOS DIREITOS AUTORAIS NO ORDENAMENTO JURÍDICO}

A propriedade intelectual abrange os direitos autorais; o direito de propriedade industrial além de outros direitos sobre bens imateriais sui generis. Os bens imateriais sui generis abrangem as topografias de circuitos integrados, as cultivares e os conhecimentos tradicionais. (BARBOSA, 2010)

A lei 9.610 de 1998 trata do tema dos direitos do autor, como obras literárias, composições musicais, audiovisuais e fotográficas, bem como o software. No entanto, a lei que é de 1998 não tratou das redes sociais e de todos os problemas que poderiam advir do uso desenfreado da internet.

O direito autoral trata das criações intelectuais, artísticas ou literárias, garantindo a proteção aos seus autores quanto ao uso incorreto ou ilícito de suas obras. Como forma de garantia do direito autoral tem-se o direito moral do autor, que está relacionado ao nome atribuído à criação de sua obra. Já o direito patrimonial está relacionado à indenização ou pagamento decorrente desse direito. (SILVA, 2019).

Quanto a classificação do direito autoral, cumpre salientar que se trata de bem móvel, no qual os negócios realizados sob essa ótica devem ser interpretados de maneira restritiva. (arts. $3^{\circ}$ e $4^{\circ}$ da lei).

Assim, considera-se como obra protegida pela lei 9.610 de 1998 aquelas que decorrem das criações do espírito, expressas por qualquer meio ou fixadas em qualquer suporte, tangível ou intangível podendo ser: textos de obras literárias, artísticas ou científicas; conferências, alocuções, sermões e outras obras da mesma natureza; as obras dramáticas e dramático-musicais; as obras coreográficas e pantomímicas, cuja execução cênica se fixe por escrito ou por outra qualquer forma; as composições musicais, tenham ou não letra; as obras 
audiovisuais, sonorizadas ou não, inclusive as cinematográficas; as obras fotográficas e as produzidas por qualquer processo análogo ao da fotografia; as obras de desenho, pintura, gravura, escultura, litografia e arte cinética; as ilustrações, cartas geográficas e outras obras da mesma natureza; os projetos, esboços e obras plásticas concernentes à geografia, engenharia, topografia, arquitetura, paisagismo, cenografia e ciência; as adaptações, traduções e outras transformações de obras originais, apresentadas como criação intelectual nova; os programas de computador; as coletâneas ou compilações, antologias, enciclopédias, dicionários, bases de dados e outras obras, que, por sua seleção, organização ou disposição de seu conteúdo, constituam uma criação intelectual. (art. $7^{\circ}$ )

Ainda, o art. $7^{\circ}$ da lei descreve em seu parágrafo $1^{\circ}$ que os programas de computador serão objeto de legislação específica. Assim, a lei 9.609 de 1998 trata dos programas de software e prevê em seu art. $1^{\circ}$ o conceito de "programa de computador" como

a expressão de um conjunto organizado de instruções em linguagem natural ou codificada, contida em suporte físico de qualquer natureza, de emprego necessário em máquinas automáticas de tratamento da informação, dispositivos, instrumentos ou equipamentos periféricos, baseados em técnica digital ou análoga, para fazê-los funcionar de modo e para fins determinados.(art. $1^{\circ}$ lei 9.608/1998).

Prevê a referida lei que não se aplicam o direito moral do autor aos programas de computador. (art. $2^{\circ}$ da lei 9.608/1998) no entanto, a lei ressalva o direito do criador do programa em questionar acerca das alterações não autorizadas de sua obra. Importante lembrar que as criações elaboradas durante contrato de trabalho ficarão sob a propriedade do empregador, conforme prevê o art. $4^{\circ}$, podendo ainda o contrato de trabalho prever de modo diverso.

No entanto, na lei acima citada não há menção específica sobre os programas que possuem a capacidade de criar novas obras a partir de uma base de dados, o que ocorre atualmente com muita frequência, principalmente por meio de aplicativos vinculados às redes sociais que manipulam ou alteram imagens, sons e vídeos.

Mário Furlaneto Neto explica que o uso da informática permite o cometimento de novos delitos e potencializam alguns outros que já existiam antes da internet se tornar popular, bem como os ilícitos quanto ao uso indevido de obras artísticas ou literárias. (FURLANETO NETO, GUIMARÃES, 2003) 
Acerca dos crimes que violam a intimidade e os direitos autorais do usuário, tem-se diversos aplicativos e redes sociais em que isso pode ocorrer, como o whatssapp, o facebook, instagram, twitter, outlook, Pinterest, sites de jogos online, youtube, spotify, e demais aplicativos que complementam essas redes sociais acima mencionadas. (MARCIAL, 2010)

Através das redes sociais disponíveis tem-se a maior troca de informações, a aproximação de pessoas, a interação entre pessoas que moram em locais distantes, mediante o compartilhamento de fotos, músicas, mesmos hobbies e etc. Assim, pode-se afirmar que as redes sociais são uma estrutura composta por pessoas e software. Aplica-se as redes sociais as regras pertinentes ao Código de Defesa do consumidor, eis que todos os usuários estão sujeitos à publicidade veiculada nessas ferramentas. O contrato eletrônico não é novidade para a sociedade, eis que se trata de uma representação virtual de uma obrigação pactuada entre as partes.

Com o crescimento exponencial de aplicativos e sistemas de software que permitem ao usuário a criação de obras intelectuais, discute-se sobre a real propriedade da obra criada, eis que quando criada via aplicativos pode ser considerada uma junção de inúmeros trabalhos, de pessoas diferentes, para se chegar a um produto final. Humberto Alves de Vasconcelos Lima explica sobre o tema:

\footnotetext{
Afirma-se que propriedade intelectual é o conjunto de direitos relativos a obras literárias, científicas e artísticas (direitos de autor), às interpretações, execuções e difusão dos mesmos (direitos conexos), bem assim os direitos atinentes às invenções - expressão utilizada aqui em sentido amplo - marcas, indicações geográficas e à proteção contra a concorrência desleal (propriedade industrial). (LIMA, 2019)
}

Discute-se sobre a possibilidade de direito de autor decorrente de criações realizadas via programas de internet, desde canções, desenhos, artes gráficas de todas as formas, até mesmo o direito autoral do criador de uma piada. Com isso, nasce a necessidade de se proteger o cidadão em relação ao uso de seus dados pessoais e garantir que o autor de uma obra seja o real detentor de seus direitos.

Atualmente existe uma judicialização do direito autoral da piada, sob a acusação de plágio, ante o crescimento do stand up comedy, dos canais de youtube voltados a comédia, das 
páginas de internet voltados ao humor. ${ }^{6}$ Discute-se até mesmo o direito de autoria da piada, pois via de regra não é necessário que se tenha uma autorização para divulgá-la.

Duarte e Pereira explicam que não é necessário solicitar uma licença, "dado que o uso público de uma obra protegida está condicionado à expressa e prévia autorização do titular, pessoa física ou jurídica, quando os direitos foram negociados". (DUARTE, PEREIRA, 2009).

Assim, surgem os questionamentos acerca da propriedade do direito autoral decorrente da criação de obras através das novas tecnologias de inteligência artificial, como o uso de softwares, aplicativos e demais programas que possuem a capacidade de alterar imagens, sons e vídeos.

\section{O DIREITO AUTORAL NA INTELIGÊNCIA ARTIFICIAL}

Indaga-se acerca dos direitos autorais decorrentes de obras escritas em blogs, fóruns, ou ainda realizada por meio de aplicativos que permitem a criação de obras audiovisuais ou composições musicais. A questão do direito autoral decorrente de obras criadas através de softwares que se utilizam da inteligência artificial traz a questão da intervenção humana. A lei de direito autoral traz desde a sua publicação a definição de obra intelectual como a criação do "espírito, de qualquer modo exteriorizada". (SANTOS, JABUR, ASCENSÃO, 2020)

Assim, percebe-se que desde o início o legislador classificou a criação artística como manifestação do espírito humano.

Uma consequência do pressuposto da intervenção humana foi a discussão sobre a
possibilidade de criaçães geradas por animais serem protegidas como obras
intelectuais, tema recentemente muito explorado, sobretudo pelo caso das fotos
tiradas por um macaco da Indonésia durante o trabalho do fotógrafo David Slater.
Essa discussão foi objeto de um processo judicial nos Estados Unidos onde o
tribunal entendeu que objeto do Direito de Autor são exclusivamente criações
humanas180. O Copyright Office dos Estados Unidos estabeleceu a exigência da
autoria humana para registro de obras intelectuais. (SANTOS, JABUR,
ASCENSÃO. 2020, p.28)

A reprodução de obras intelectuais e audiovisuais pela internet abrangem os três campos fundamentais das obras que são o da reprodução, o da distribuição e o da

\footnotetext{
${ }^{6}$ ÉPOCA NEGÓCIOS. Acusado de Plágio criador de gina indelicada admite cópia de piadas. Disponível em $<<$ https://epocanegocios.globo.com/Informacao/Dilemas/noticia/2012/08/acusado-de-plagio-criador-de-ginaindelicada-admite-copia-de-piadas.html > acesso em 25.set.2010.
} 
comunicação ao público. Costa Netto explica que "A rede mundial de computadores (internet) engloba esses três campos de utilização de obras intelectuais." (COSTA NETTO, 2010, p.333)

No ambiente da internet houve grande debate sobre o controle dos direitos autorais, e em quais modalidades de utilização seriam de propriedade de seus titulares, pois na difusão do acesso à internet os provedores facilitaram o acesso à reproduções ilícitas obras literárias, audiovisuais e sonoras. No entanto, esse debate girou em torno da reprodução ilícita das obras, e não da criação por tecnologias de inteligência artificial, que é o tema deste trabalho.

No ano de 2000 foi decidido em Paris acerca da composição musical assistida por um computador, em que, havendo intervenção humana será entendida como criação de obra original. Dessa forma, entende-se que a criação elaborada por programas de softwares são apenas a ferramenta de uso do criador, são as denominadas Computer Assisted works". Perceba-se que toda vez que um programa de computador ou aplicativo for utilizado para a criação artística, estar-se-á diante de uma ferramenta a disposição do ser humano, merecendo a obra fruto desse trabalho proteção igualitária. (SANTOS, JABUR, ASCENÇÃO, 2020. p.29)

Por outro lado, existem as "Computer Generated Works", que são softwares que geram a criação intelectual. Nesta classificação tem-se as obras criadas por alternativas prédefinidas, havendo uma relação de causalidade entre o sujeito que programa, o que utiliza e o resultado final. Outra forma de criação pelo "Computer Generated Works" é o sistema que se utiliza de tecnologias de inteligência artificial, criando novas obras. Neste tipo de software, o programa se utiliza de uma base de dados, que por sua vez auxilia na criação "inexistindo uma relação de causalidade direta entre o programador ou usuário do software e o resultado gerado pelo sistema”. (SANTOS, JABUR, ASCENÇÃO, 2020. p.29)

Exemplo desse software é o "Next Rembrandt Project" que cria obras ao estilo de Rembrandt por meio de data mining ${ }^{7}$ e machine learning. Este programa se utiliza de uma base de dados para criar novas obras ao estilo do pintor. (SANTOS, JABUR, ASCENÇÃO, 2020. p.30) Dessa forma, questiona-se: poderia o programador reclamar o direito autoral pela criação da obra? Ou seriam os proprietários do software? Ou ainda, o comprador da obra criada ao estilo do famoso pintor?

\footnotetext{
${ }^{7}$ Prospecção de dados ou mineração de dados, é a procura de padrões consistentes em um conjunto de dados.
} 
Por um lado, não poderia o programador ser considerado o autor da obra, conforme Santos, Jabur e Ascenção explicam: “o Direito de Autor não protege as criações "acidentais”, ou seja, aquelas que não resultam de um projeto de obra e a interatividade não altera essa premissa quando se trata de analisar o impacto das novas tecnologias no processo de criação". (SANTOS, JABUR, ASCENÇÃO, 2020. p.30)

Os autores explicam que o sujeito que programa ou cria o software não poderia ser considerado como autor eis que não participa diretamente ou indiretamente da sucessão de atos necessários par que seja elaborada a obra. Apenas a pessoa que participa da cadeia de atos necessários na criação poderia ser considerada autora.

Dessa forma, pode-se inferir que a obra criada inteiramente por programas de computador, sem a assistência humano para o ato de elaboração e criação, não teria proteção da lei de direitos autorais. No entanto, a grande dificuldade está em encontrar em qual (is) ato (s) houve efetivamente a intervenção humana, e ainda, quem seria o responsável para verificar o nível de contribuição do sujeito? Por exemplo, cite-se o projeto que cria obras ao estilo de Rembrandt, se por acaso a pessoa tem a iniciativa de procurar uma foto de paisagem e inserir no programa, então esta pessoa seria a criadora da obra apenas por selecionar uma foto?

O art. $5^{\circ}$ da Lei de direito Autoral, n. 9.610 de 1998 prevê que a obra original é a obra primígena. Assim, no Brasil, para que se tenha proteção da referida lei é necessário que a obra original tenha a intervenção humana, já que autor é a pessoa física criadora de obra literária, artística ou científica (art.11). A lei traz a extensão da proteção a pessoa jurídica. No entanto, não fala sobre a propriedade do direito autoral da criação decorrente do uso dos softwares.

Assim o que se tem atualmente são os questionamentos acerca da propriedade dos direitos autorais e da possibilidade de se mensurar a extensão da participação humana na criação dessas obras, podendo os casos que tratam desses temas serem levados ao poder judiciário para solução.

\section{CONCLUSÕES}

Os avanços da tecnologia agregam inúmeros benefícios à sociedade contemporânea. Entretanto, a Inteligência Artificial, sobretudo quando se fala de Machine Learning ou Deep Learning, pairam dúvidas quanto a consequências jurídicas dos atos praticas por essas 
máquinas, uma vez que a autonomia na tomada de decisão pode resultar em impasses impossíveis de ser previstos pelo desenvolvedor ou pelo proprietário do sistema.

Diversas máquinas já conseguem elaborar tarefas, resolver problemas, criar músicas e apontar soluções que até então são inexistentes no contexto social e resultam no dilema dos direitos autorais. Sabe-se que se um ser humano desenvolve uma marca ou um invento, terá a proteção da propriedade intelectual. Contudo, quando a máquina desenvolve de forma autônoma algo, em virtude de um algoritmo de Machine Learning ou Deep Learning, a situação no mundo jurídico não possui previsão de regulação.

Desde a criação da lei de direitos autorais no país houve pouca atualização quanto as inovações tecnológicas, especialmente no que diz respeito à inteligência artificial e os novos meios de criação de músicas, obras artísticas e literárias. O direito autoral possui proteção quanto ao autor da obra, seu direito moral e patrimonial, sendo conferida a tutela quanto ao uso imoderado ou ilícito da obra. No entanto, a propriedade do direito autoral decorrente de programas que se utilizam da inteligência artificial e suas bases de dados ainda não possui proteção específica.

Questiona-se acerca do grau de participação do sujeito no que tange à cadeia de atos necessários para se criar uma obra. Pois de acordo com o entendimento da lei de direito autorais, considera-se autor ou co-autor da obra aquele que participa dos eventos para a criação de nova obra literária ou científica.

É necessário que haja inovação legislativa quanto a proteção de direitos autorais decorrente do uso das novas tecnologias, para que não haja abusos ou ainda injustiça com o autor da obra. Outra questão relevante seria o modo pelo qual se analisaria quem é o autor e qual a sua contribuição, em que a lei deve indicar o responsável por tal identificação.

\section{REFERÊNCIAS}

BARBOSA, Denis Borges. Uma introdução à propriedade intelectual. $2^{\mathrm{a}}$ ed. Rio de Janeiro: Lumen Juris, 2010.Disponível em: <http://www.denisbarbosa.addr.com/arquivos/livros/umaintro2.pdf>Acesso em 17 set. 2021

BELLMAN, Richard. Artificial Intelligence: Can Computers Think?. Boston: Thomson Course Technology, 1978. 
BURRELL, J. How the machine 'thinks': Understanding opacity in machine learning algorithms Big Data \& Society, 2016. Disponível em: [http://ssrn.com/abstract=2660674]. Acesso em: 30 ago. 2021.

BRASIL. Marco Civil da Internet. Lei 12.965, de 23 de abril de 2014. São Paulo: Saraiva, 2018.

CARDIN, Valéria Silva Galdino; WOLOWSKI, Matheus Ribeiro de Oliveira. IMPLICAÇÕES JURÍDICAS DO USO DA INTELIGÊNCIA ARTIFICIAL NO PROCESSO EDUCACIONAL: PODE A MÁQUINA SUBSTITUIR UM PROFESSOR HUMANO?. Revista Juridica, [S.1.], v. 1, n. 63, p. 198 - 220, mar. 2021. ISSN 2316-753X. Disponível em: http://revista.unicuritiba.edu.br/index.php/RevJur/article/view/5139/371373158 . Acesso em: 10 set. 2021.

DAMILANO, C. T. Inteligência artificial e inovação tecnológica: as necessárias distinções e seus impactos nas relações de trabalho / Artificial intelligence and technological innovation: the necessary distinctions and their impacts in work relations. [s. 1.], 2019. DOI 10.34117/bjdv5n10-200. Disponível em: https://search.ebscohost.com/login.aspx?direct=true \&db=edsbas\&AN=edsbas.2F1BBB0C\&la

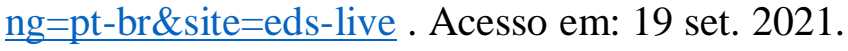

DUARTE, Eliane Cordeiro de Vasconcellos Garcia; PEREIRA, Edmeire Cristina. DIREITO AUTORAL, PERGUNTAS E RESPOSTAS. UFPR, 2009.

ÉPOCA NEGÓCIOS. Acusado de Plágio criador de gina indelicada admite cópia de piadas. Disponível em $<<$ https://epocanegocios.globo.com/Informacao/Dilemas/noticia/2012/08/acusado-de-plagiocriador-de-gina-indelicada-admite-copia-de-piadas.html >> acesso em 25.set.2020.

EUROPEAN COMISSION. Communication Artificial Intelligence for Europe, 2018. Disponível em: https://ec.europa.eu/digital-single-market/en/news/communication-artificialintelligence-europe Acesso em: 18 set. 2021.

FELIPE, Bruno Farage da Costa; PERROTA, Raquel Pinto Coelho. INTELIGÊNCIA ARTIFICIAL NO DIREITO - UMA REALIDADE A SER DESBRAVADA. In: Revista de Direito, Governança e Novas Tecnologias, v.4, n. 1, p. 01-16, jan/jun 2018. Disponível em: https://www.indexlaw.org/index.php/revistadgnt/article/view/4136 Acesso em: 17 set. 2021.

FURLANETO NETO, Mário; GUIMARÃES, José Augusto Chaves. Crimes na internet: elementos para uma reflexão sobre a ética informacional. R. CEJ, Brasília, n. 20, p. 67-73, jan./mar. 2003 Disponível em: <http://www.cjf.jus.br/revista/numero20/artigo9.pdf Acesso em 16 jun.2021 
GARCÍA-PEÑALVO, F. J. Una introducción a la inteligencia artificial. [s. 1.], 2019. DOI 10.5281/zenodo.3164370.

https://search.ebscohost.com/login.aspx?direct=true\&db=edsbas\&AN=edsbas.C7258344\&lan $\mathrm{g}=\mathrm{pt}$-br\&site=eds-live. Acesso em: 17 set. 2021.

GELICIC, R. Lenguajes artificiales: Un análisis a los aportes de Alan Turing (Artificial languages: An analysis to the contributions of Alan Turing). [s. 1.], 2018. DOI 10.5281/zenodo.2617353. Disponível em: https://search.ebscohost.com/login.aspx?direct=true \&db=edsbas\&AN=edsbas 77FDF88E\&lang=pt-br\&site=eds-live. Acesso em: 17 set. 2021.

HAUGELAND, John. Artificial intelligence: The very idea. Cambridge: Mit, 1985.

KURZWEIL, Ray. The Age of Intelligent Machines. Cambridge: Mit Press, 1990.

LIMA, Humberto Alves de Vasconcelos. PROPRIEDADE INTELECTUAL NO SÉCULO XIX: EM BUSCA DE UM NOVO CONCEITO E SUBSTRATO TEÓRICO. Revista da Faculdade de Direito UFPR, Curitiba, PR, Brasil, v. 56, dez. 2012. ISSN 2236-7284. Disponível em: <https://revistas.ufpr.br/direito/article/view/33495/21037>. Acesso em: 27 set. 2019.

MAGALHÃES, Renato Vasconcelos. Inteligência Artificial e Direito - Uma breve introdução histórica. In: Revista Direito e Liberdade, Mossoró, v.1, n1. p.355-370, jul/dez, 2005.

MARCIAL, Fernanda Magalhães. Os Direitos Autorais, sua proteção, a liberalidade na internet e o combate à pirataria. In: Âmbito Jurídico, Rio Grande, XIII, n. 75, abr 2010.

Netto, J.C. C. Direito autoral no Brasil. [Digite o Local da Editora]: Editora Saraiva, 2019. 9788553611089. Disponível em: https://integrada.minhabiblioteca.com.br/\#/books/9788553611089/. Acesso em: 2021 set. 19.

PAULICHI; Jaqueline Silva; CARDIN, Valéria Silva Galdino. DAS FORMAS DE INTELIGÊNCIA ARTIFICIAL E OS IMPACTOS NOS PADRÕES DE CONSUMO E A PROTEÇÃO DOS DIREITOS DA PERSONALIDADE. Revista Meritum, v.15, n.4, p.228245, 2020. Disponível e: http://revista.fumec.br/index.php/meritum/article/view/7954 Acesso em: 17 set. 2021.

ROSS. Artificial Intelligence (AI) for the practice of law: An introduction. Disponível em: https://blog.rossintelligence.com/post/ai-introduction-law Acesso em: 28 ago. 2021.

RUSSELL, Stuart; NORVIG, Peter. Artificial Intelligence: A Modern Approach. 3. ed. New York City: Pearson, 2009. 
SANTOS, Manoel J. Pereira dos. JABUR, Wilson Pinheiro. ASCENSÃO, José de Oliveira. Direito autoral. 2. ed. São Paulo: Saraiva Educação, 2020.

SILVA, Carolina Brasil Romão. A INDÚSTRIA DOS JOGOS ELETRÔNICOS: NOVAS TECNOLOGIAS, PROPRIEDADE INTELECTUAL E CENÁRIO MUNDIAL E BRASILEIRO. Revista de Direito, Inovação, Propriedade Intelectual e Concorrência. eISSN: 2526-0014. Goiânia.v. 5. n. 1 p. 1-20 Jan/Jun. 2019.

SOARES, Marcelo Negri; KAUFFMAN, Marcos Eduardo; CHAO, Kuo-Ming; SAAD, Maktoba Omar. New Technologies and the Impact on Personality Rights in Brazil. In: Revista Pensar, Fortaleza, v.25, n.1, p.1-12, jan/mar, 2020. Disponível em: https://periodicos.unifor.br/rpen/article/view/9969 Acesso em: 08 set. 2021.

STAATS, Sabrina Daiane. O dever de proteção aos direitos fundamentais frente a utilização de Inteligência Artificial no poder judiciário. In: Revista Brasileira de Inteligência Artificial e Direito - RBIAD, v. 1, n. 1, p. 1-18, 2020. Disponível em: https://rbiad.com.br/index.php/rbiad/article/view/3 Aceso em: 18 set. 2021.

TEIXEIRA, Tarcísio. Curso de direito e processo eletrônico: doutrina, jurisprudência prática. 4. ${ }^{\text {a }}$ ed. atual. e ampl. São Paulo: Saraiva Educação, 2018. 